\title{
The Language of Cambridge...
}

\section{Corpus Linguistics \\ Investigating Language Structure \\ and Use \\ Douglas Biber, \\ Susan Conrad, and \\ Randi Reppen}

This book is about investigating the way people use language in speech and writing. It introduces the corpus-based approach to the study of language, based on analysis of large databases of real language examples and illustrates exciting new findings about language and the different ways that people speak and write.

Cambridge Approaches to Linguistics

49957-7 Paperback $\$ 19.95$

\section{The Rise and Fall of Languages \\ R.M.W. Dixon}

"This book is required reading for anyone seriously interested in what we can honestly recover from the past history of languages."

-James A. Matisoff,

University of California, Berkeley

"This book will be seminal in bringing about a paradigm shift in historical linguistics."

—Randy J. LaPolla,

Academia Sinica Taiwan and

City University of Hong Kong

This book puts forward a new approach to language change, the punctuated equilibrium model. This is based on the premise that during most of the 100,000 or more years that humans have had language, states of equilibrum have existed during which linguistic features diffused across the languages in a given area so that they gradually converged on a common prototype. From time to time, the state of equilibrium would be punctuated, with the expansion and split of peoples and of languages.

62654-4 Paperback \$16.95
Phonological

Representations

Their Names, Forms and Powers John Coleman

This book reviews current theories of the sound-structure of words and syllables.

Dr. Coleman presents technical arguments showing that the contemporary theories are too complex and that a simpler theory, Declarative Phonology, is adequate. This theory is exemplified with detailed accounts of the sound-structure of words and syllables in English and Japanese.

Cambridge Studies in Linguistics

47208-3 Hardback \$74.95

\section{The Cambridge Encyclopedia of the English Language David Crystal \\ "You can open it to any page and be enthralled." -Indianapolis News}

This celebrated book offers a unique experience of the English language in all its richness and diversity. Clear and accessible, it abounds with insights into how the language evolved and how it works. Superbly illustrated in color throughout, and updated for this first paperback edition, The Cambridge Encyclopedia of the English Language is the most comprehensive general reference book on the history, structure, and worldwide use of English ever written.

59655-6 Paperback \$27.95

\section{The Dynamics of Focus Structure \\ Nomi Erteschik-Shir}

This book explores the role of focusing in natural language sentences and the role of this basic cognitive mechanism in explaining sentence stress, meaning and structure. The result is an innovative view of our linguistic competence.

Cambridge Studies in Linguistics 84 $59217-8$ Hardback $\$ 64.95$ 


\section{and CSLI}

\section{Forthcoming from CSLI... Learnable Classes of Categorial Grammars Makoto Kanazawa}

This book investigates learnability of various classes of classical categorical grammars within the Gold paradigm of identification in the limit from positive data. Learning from structures and learning from flat strings are considered. The learning algorithms used in this work build on Buszkowski and Penn's algorithm for finding categorial grammars from input consisting of functorargument structures.

Studies in Logic, Language and Information 1-57586-096-1 Paperback \$22.95

\section{Linguistic Databases \\ John Nerbonne, Editor}

Contributors: Andrew Bredenkamp, Gerard

Chollet, Oliver Christ, Jean-Luc Cochard, Andrei Constantinescu, Werner A. Deutsch, Siobhan Deulin, Erik Fudge, Sylviane Granger, Edgar Haimerl, Cedric Jaboulet, Judith Klein, Philippe Langlais, Jacques Le Maitre, Sylvia Moosmüller, Elisabeth Murisasco, Klaus Netter, Anton Noll, Stephen Oepen, Monique Rolbert, Louisa Sadler, Linda Shockey, Gary F. Simons, Andrew Spencer, John Tait, John V. Thomson, Martin Volk, RalfVollman

CSLI Lecture Notes

1-57586-092-9 Paperback \$24.95

\section{Parsing Below the Segment in a Constraint-Based Framework \\ Cheryl Zoll}

This book proposes a new way of understanding the behavior of consonants and vowels in a broad cross-section of the world's languages. Dissertations in Linguistics

1-57586-130-5 Paperback \$24.95

\section{Discourse and Cognition Bridging the Gap Jean-Pierre Koenig, Editor}

The collection includes work from cognitive science disciplines whose concerns overlap with linguistics, such as artificial intelligence, neurolinguistics and psychology.

Contributors: Knud Lambrecht, Laura A. Michaelis, Mark Tumer, Gilles Fauconnier, Boris Fridman-Mintz, Scott K. Liddell, Adele E. Goldberg, Scott A. Schwenter, Jean-Pierre Koenig, Beate Benndorf, Maria Polinsky, Ilana Mushin, Catherine L. Harris, Friederike Braun, John A. Barnden, Patrick Farrell, Alan Cienki,

Hengameh Irandoust, Tuomas Huumo, Vivienne Fong, Christine Poulin, William Byrne, Ronald W. Langacker, George Lakoff, Rafael Núñez, Sarah Taub, Adrian Robert, Mira Ariel, Robert S. Kirsner, Willem A. van der Kloot, Joe Grady, Joost Schilperoord, Arie Verhagen 1-57586-114-3 Paperback \$27.95

\section{Morphology and} Its Relation to Phonology and Syntax

\section{Steven G. Lapointe,}

Diane K. Brentari, and

Patrick M. Farrell, Editors

Leading experts in the field have contributed to this volume, which explores key issues in current morphology and the interactions of morphology with phonology and syntax. Contributors: Mark Aronoff, Mark C. Baker, Hagit Borer, Diane Brentari, Andrew CarstairsMcCarthy, Patrick Farrell, Sharon Inkelas, Richard D. Janda, Steven G. Lapointe, Rochelle Lieber, Rolf Noyer, C. Orhan Orgun, David M. Perlmutter, Jerrold M. Sadock, Peter Sells, Margaret Speas, Andrew Spencer, Gregory Stump, Moira Yip

Distributed for CSLI Publications

1-57586-112-7 Paperback \$27.95 


\section{Language Variation and Change}

\section{NOTES FOR CONTRIBUTORS}

Language Variation and Change publishes original research reports that are based on data of language production, either oral or written, from contemporary or historical sources. Articles with substantive content are preferred over those that are solely argumentative; those that synthesize or reanalyze a number of research findings on substantive issues will also be considered. Conforming to scientific methodology, the reported findings should be fully replicable from the information provided.

Contributions may be submitted from all countries. The usual language of publication is English, although articles in French are also welcome. All submissions should be sent, in triplicate, to:

David Sankoff

\section{Language Variation and Change}

Centre de recherches mathématiques

Université de Montréal

C.P. 6128, Succursale Centreville

Montréal H3C 3J7, Canada

Submission of an article is taken to imply that it has not been previously published or is not being considered for publication elsewhere. If an author is publishing a related article, this fact should be stated.

Copyright. Contributors of accepted articles will be asked to assign their copyrights, on certain conditions, to Cambridge University Press, to help protect their material, particularly in the U.S.A.

\section{Manuscript Preparation and Style}

Manuscripts should be clearly typed on $81 / 2^{\prime \prime} \times 11^{\prime \prime}$ or A4 white bond paper. The inclusion of microcomputer diskettes containing text, artwork, and appropriate software, along with the hard copy, may facilitate editing. The entire manuscript-including abstract, endnotes references, and tables - must be double-spaced and numbered consecutively. The Editor may find it necessary to return manuscripts for reworking or retyping that do not conform to the journal's requirements. The article should be arranged as follows:

Title Page (page 1). To facilitate blind reviews, all indication of authorship must be limited to this page. Other pages must only show the short title plus page number in the upper right corner. The title page includes (a) full title, (b) names and affiliations of all authors, (c) mailing address and phone number of the lead author, (d) address to which offprints should be sent (if not the lead author), (e) short title of less than 50 characters.

Abstract (page 2). Include the full title and the abstract. Abstracts should not exceed 150 words.

Acknowledgments (page 2). Place below the abstract. Use this section to indicate any grant support, substantial assistance in the preparation of the article, or any other author notes.

Text (page 3). Use a 5-character paragraph indent. Do not hyphenate words or justify the right margin. Underscore material that is to be italicized in print. Glosses should be placed within single quotation marks.

References are to be made in the text (not in the endnotes) by giving in parentheses the name of the author, year of publication, and, where relevant, the page(s) referred to:
(Vincent, 1982:90-91). If the author's name is part of the text, the following form should be used: "Vincent (1982) listed several...." For multi-authored works, only the first citation should list all authors: (Weinreich, Labov, \& Herzog, 1968). In subsequent citations, only the first name should be given, followed by "et al.": (Weinreich et al., 1968). Separate works referred to in the same parentheses should be listed in alphabetical order; those by the same author should be separated by commas, and those by different authors by semi-colons: (López Morales, 1981; Vincent, 1981, 1982). Initials should be used (before the author's name) only when it is necessary to distinguish between two or more authors with the same surname referred to in the same article.

All works referred to in the text must be listed in the reference section, double-spaced, and in alphabetical order. Examples of references (note the use of punctuation marks within references):

Cedergren, Henrietta J. (1973). Interplay of social and linguistic factors in Panama. Ph.D. dissertation, Cornell University.

López Morales, Humberto. (1981). Velarization of $/ n /$ in Puerto Rican Spanish. In D. Sankoff \& H. J. Cedergren (Eds.), Variation omnibus. Edmonton: Linguistic Research. 105-113.

Tagliamonte, Sali, \& Poplack, Shana. (1980). How Black English Past got to the present: Evidence from Samaná. Language in Society 17:513-533.

Vincent, Diane. (1982). Pressions et impressions sur les sacres au Québec. Montréal: Office de la langue française.

Endnotes may be used when more than a simple citation is required. Notes should be numbered consecutively throughout the text and typed together on a separate page preceding the reference section.

Tables. Tables must appear as a unit following the reference section. Each table should be typed, doublespaced, on a separate sheet, numbered consecutively with an Arabic numeral and a short title. All tables must be cited in the text.

Figures. Figures must appear as a unit following the tables. Figures must be ready for photographic reproduction: for photographs, an $8^{\prime \prime} \times 10^{\prime \prime}$ glossy; or for diagrams, professionally rendered or computer generated. All labels and details must be clearly printed and large enough to remain legible at a 50\% reduction. Each figure must be numbered consecutively with an Arabic number. Descriptive legends must be typed together, double-spaced, on a separate sheet preceding the artwork. Artwork should be identified by number and title on the back and carefully packaged in a protective envelope. All figures must be cited in the text.

\section{Proofs}

First proofs will be sent to the lead author who will be expected to correct and return them to Cambridge, by airmail where appropriate, within 3 days of receipt.

\section{Offprints}

25 offprints of the article will be provided free of charge to the lead author. Additional offprints may be purchased if ordered at the proof stage. 


\section{\&anguage Variation and Change}

Volume 10 Number 11998

\section{CONTENTS}

\section{LEONIE CORNIPS}

Syntactic variation, parameters, and social distribution

\section{Christer Geisler}

Infinitival relative clauses in spoken discourse

\section{RICHARD CAMERON}

A variable syntax of speech, gesture, and sound effect:

Direct quotations in Spanish 